\title{
O processo antes da reforma: sobre algumas principais referências que subsidiaram a reforma do processo de Bolonha Europeu
}

The process before the reform: about some main references that support the reform of the European Bologna process

Ralf Hermes Siebiger

Universidade do Estado de Mato Grosso

Universidade Federal da Grande Dourados

\section{Resumo}

processo de Bolonha, movimento contemporâneo de reforma da educação superior europeia, tornou-se conhecido como tendo seu início a partir da assinatura das declarações de Sorbonne (1998) e Bolonha (1999). Contudo, essa reforma fundamenta-se também numa série de expedientes sobre educação superior que, desde os primeiros anos pós-segunda guerra mundial, foram emitidos conjuntamente às demais políticas de reconstrução e unificação do continente europeu. Considerando a incipiente menção a essas referências na literatura produzida no Brasil sobre o processo de Bolonha, a presente discussão busca apresentar algumas dessas principais referências, bem como evidenciar em que medida subsidiaram e mesmo foram incorporadas a essa reforma.

Palavras-chave: Processo de Bolonha. Reforma da educação superior europeia.

Precedentes referenciais.

\begin{abstract}
The Bologna process, a contemporary movement for reform of European higher education, became known as having its beginning from the signing of declarations of Sorbonne (1998) and Bologna(1999). However, this reform is based also on a series of expedients to higher education which, from the early post-World War II years, were issued in conjunction with other policies of reconstruction and unification of the European continent. Considering the incipient mention of these references in the literature produced in Brazil on the Bologna process, the present discussion seeks to present some of these main references, as well as demonstrates in what extent subsidized and even incorporated in this reform.

Keywords: Bologna process. Reform of European higher education. Precedent references.
\end{abstract}




\section{Introdução}

No que se refere a reformas no campo da educação, Dias Sobrinho (2009) ressalta que se trata, basicamente, de construções de um quadro legal e burocrático, geralmente proposto por políticos, para responder a determinados problemas e produzir efeitos mais ou menos coerentes com projetos mais amplos de um governo ou de um sistema de poder. Nessa linha, situa-se o chamado "processo de Bolonha", que expressa o movimento contemporâneo de reforma da educação superior europeia,e que tem por objetivo estabelecer um Espaço Europeu de Educação Superior (EEES). Trata-se de uma política supranacional europeia para a educação superior que, atualmente, dispensa maiores apresentações, considerando já haver uma expressiva produção sobre o tema na literatura especializada, inclusive algumas incursões em nível de teses e dissertações.

De maneira geral, tal processo de reforma tornou-se conhecido foi iniciado a partir da assinatura das declarações de Sorbonne (1998) e Bolonha (1999). No entanto, a reforma se inspira e se fundamenta numa série de expedientes sobre educação superior que, desde os primeiros anos pós-segunda 36 guerra mundial, foram emitidos conjuntamente às demais políticas de reconstrução e unificação do continente europeu. Observa-se, nesse processo histórico, a adoção de um substancial contingente de políticas, acordos, relatórios e outras medidas, publicadas por várias instâncias e níveis de influência e/ou de decisão (aqui entendidos como "referências"), que contribuíram para o objetivo de se construir uma integração europeia também na esfera educacional.

Sobre essa questão, o que se verifica é ainda uma incipiente menção a essas referências na literatura produzida no Brasil sobre a respectiva reforma. Nesse sentido, o propósito dessa discussão consiste em apresentar um resgate de suas bases fundamentais, esclarecendo que o processo de Bolonha não se inicia propriamente a partir das declarações de Sorbonne e de Bolonha, e sim, sustenta-se no próprio movimento histórico de criação das primeiras comunidades econômicas europeias a partir da década de 1950, referenciando-se, para tanto, em uma série de acordos e programas em curso, bem como em relatórios e conferências realizados sob a coordenação de organismos multilaterais, como exposto a seguir.

Essa discussão é fruto de pesquisa desenvolvida em nível de Mestrado' na área de Educação, a qual teve por objetivo identificar aproximações entre o 
movimento de reforma do processo de Bolonha e as recentes medidas pontuais de reestruturação da educação superior brasileira, evidenciando, em determinados aspectos, pressupostos semelhantes no encaminhamento de mudanças em ambos os contextos. Nesse artigo, o foco, contudo, é na reforma europeia, apresentando-se alguns de seus principais antecedentes referenciais.

\section{Antecedentes referenciais da reforma do processo de Bolonha}

Considerando os diversos níveis, instâncias, agentes e contextos que desencadearam o processo de Bolonha, organizou-se a exposição desse histórico, cronologicamente, em duas fases ${ }^{2}$.

I - Primeira Fase - 1953 a 1985 - Nessa primeira fase, enfatiza-se o domínio das instâncias responsáveis pelos documentos aqui citados, uma vez que os principais expedientes sobre educação superior publicados nesse período se restringem à abrangência político-territorial das comunidades e entidades que os emitiram, considerando o movimento de reestruturação econômica da Europa no período imediatamente após o término da segunda guerra mundial.

Nesse sentido, o primeiro movimento com vistas ao estabelecimento de uma política de reunificação e recuperação econômica europeia diz respeito à criação, em 1951, da Comunidade Europeia do Carvão e do Aço - CECA (COMISSÃO EUROPEIA, 1997).

Desde a década de 1950, após a Segunda Guerra Mundial, tanto as medidas econômicas de reestruturação do continente europeu como as políticas sociais começaram a ser pensadas em nível supranacional. Registra-se, para tanto, a realização da Conferência de Messina, em 1955, na qual se defendeu uma concepção de universidade dotada de "mentalidade europeia", baseada em uma aproximação entre a instituição universitária e a formação em nível superior com o próprio movimento de expansão da comunidade. Dessa conferência, resultou também o Tratado de Roma, que transformaria a CECA na Comunidade Econômica Europeia - CEE, em 1957, expandido os setores econômicos de negociação abrangidos pela comunidade. (COMISSÃO EUROPEIA, 1997; WEIDENFELD; WESSELS, 1997; RIEDO; PEREIRA, 2009).

Ainda nos anos de 1950, surgiram as primeiras convenções sobre equivalência e reconhecimento tanto de estudos como de qualificações acadêmicas, que culminariam, já na década de 1960, no surgimento de propostas 
de maior cooperação europeia nos domínios do ensino e da pesquisa, e de maior aproximação entre a natureza da formação acadêmica e as características das atividades profissionais.

Nesse sentido, o Conselho Europeu ${ }^{3}$ tornou-se a primeira instância a estabelecer diretrizes sobre educação superior desde a criação da CECA e da CEE. Embora não exerça função legislativa, o Conselho opera por meio da expedição de convenções, que, por sua vez, são ratificadas, individualmente, pelos Estados-membros. Para tanto, no que tange à educação superior, expediu as seguintes convenções:

- Convenção Europeia sobre Equivalência de Diplomas que dão acesso a Estabelecimentos Universitários (1953), e seu Protocolo Adicional (1964). (PORTUGAL, 1981).

- Convenção Cultural Europeia (1954), com o objetivo de promover a integração cultural por meio do estudo das línguas, da história e da civilização dos Estados-membros, desenvolvimento de estudos e a participação em atividades culturais, facilitando a circulação de pessoas entre os países signatários. (PORTUGAL, 1954).

- Convenção Europeia sobre Equivalência de Períodos de Estudos Universitários (1956), relativa ao reconhecimento de períodos de estudo de línguas vivas realizados nas universidades dos respectivos países signatários.

- Convenção Europeia sobre o Reconhecimento Acadêmico de Qualificações Universitárias (1 959), que propôs, entre as partes contratantes - quer seja o Estado-membro, a universidade, ou ambos - o reconhecimento acadêmico mútuo de habilitações universitárias. (PORTUGAL, 1959).

De maneira geral, essas Convenções tiveram por característica a defesa de uma política antes indutiva que mandatária, uma vez que se estabelecem em nível supranacional, sendo facultada, aos Estados-membros, sua adesão.

Nessa trajetória, em 1959, realizou-se a primeira reunião da Conferência Europeia de Reitores, com o objetivo de se discutir propostas relativas a acordos formais entre as universidades no âmbito da já constituída CEE. Posteriormente, em 1961, a Declaração de Bonn, assinada pelos então presidentes e primeiros-ministros da Comunidade, estabeleceu que o movimento de cooperação e integração europeia devesse incluir os domínios da instrução, 
cultura e pesquisa. (RIEDO; PEREIRA, 2009). E, em 1963, o Conselho da CEE publicou a Decisão 63/266/CEE, que buscou assegurar que os cidadãos europeus pudessem receber o grau mais elevado possível de formação profissional que se mostrasse necessário às suas atividades profissionais. Essa decisão teve por objetivo ampliaras opções de formação profissional disponíveis com vistas a suprir exigências de maior progresso técnico advindas do emergente período industrial iniciado na década de 1960, possibilitando, assim, o desenvolvimento social e econômico da Comunidade. (CEE, 1987).

Posteriormente, na década de 1970, a Organização das Nações Unidas para a Educação, a Ciência e a Cultura (Unesco) ${ }^{4}$ surge como protagonista desses acordos, lançando três convenções (1974, 1976 e 1979) sobre reconhecimento de estudos, diplomas e graus para, respectivamente, as regiões: 1) da América Latina e Caribe;2) dos países árabes e europeus costeiros do mar Mediterrâneo; e 3l dos países da "Região Europa da Unesco". Verifica-se que o teor dos acordos é semelhante, o que indica a prevalência de uma orientação generalizada dessa agência no que se refere às políticas de equivalência e reconhecimento, as quais, em última instância, subsidiam as ações de mobilidade acadêmica e profissional.

Em termos sucintos, as três convenções propuseram: a) abertura do acesso às instituições de ensino superior a estudantes ou pesquisadores oriundos de qualquer Estado contratante; b) reconhecimento de estudos universitários, certificados, diplomas e títulos desses acadêmicos; c) criação de terminologia e de critérios de avaliação comuns que subsidiassem a utilização de um sistema para equiparar unidades curriculares, bem como áreas de estudo, certificados, diplomas e títulos; d) adoção de formas de se considerar experiências e competências individuais, que seriam, por sua vez, avaliadas por autoridades competentes; e) adoção de critérios amplos para avaliação e reconhecimento de estudos parciais; f) aperfeiçoamento do sistema de intercâmbio de informações sobre o reconhecimento de estudos, certificados, diplomas e títulos; g) aperfeiçoamento constante dos programas de estudo, tendo em vista os imperativos de desenvolvimento econômico, social e cultural, as políticas de cada Estado-nação e as próprias recomendações da Unesco enquanto agência colaboradora e subsidiária.

Observa-se, desde 1974, o interesse da Unesco em promover estratégias para o reconhecimento de estudos universitários entre diferentes países. E é interessante notar que, de modo pioneiro, a primeira convenção foi expedida 
para abranger os países da América Latina e Caribe, tornando-se, assim, uma espécie de "piloto" para as demais convenções que estariam por vir. Nesse sentido, por meio do reconhecimento internacional desses estudos e títulos, as convenções de 1974 e 1976 buscaram ampliar a mobilidade internacional de estudantes e profissionais, bem como melhor aproveitar os recursos humanos e os meios de formação existentes na região, tendo por finalidade assegurar a empregabilidade e evitar a "fuga de cérebros" de acadêmicos dessas regiões aos países mais industrializados. Os direitos que tais convenções buscaram garantir referem-se tanto ao reconhecimento de estudos como à possibilidade de exercício profissional em quaisquer países signatários.

E, em se tratando de mobilidade, a partir da década de 1980,foram tomadas as primeiras medidas de promoção do trânsito de acadêmicos entre os países membros da então CEE.

No âmbito da Comissão Europeia ${ }^{5}$, houve a criação, em 1984, da rede dos Centros Nacionais de Informação sobre Reconhecimento Acadêmico (National Academic Recognition Information Centre) - NARIC, com a finalidade de providenciar e disponibilizar informações sobre reconhecimento de diplomas, certificados e títulos, instituições e sistemas de ensino entre países.

40 Esses centros são designados pelos Ministérios da Educação de cada país, e fornecem informações a quem tiver interesse, incluindo estudantes, diplomados, profissionais, Instituições de Educação Superior (IES), organizações nacionais e internacionais, entre outros. (CONSELHO EUROPEU, 2004).

Atualmente em plena atividade, esses centros são também responsáveis pela emissão de declarações comprobatórias acerca dos níveis de qualificações e informativos sobre as respectivas profissões de cada Estado-membro da União Europeia. Possuem também a incumbência de promover e acompanhar a aplicação da Convenção sobre Reconhecimento das Qualificações Relativas ao Ensino Superior na Região Europa (Convenção de Lisboa), vigente desde 1997. (CONSELHO EUROPEU, 2004).

E, sob competência do Parlamento Europeu ${ }^{6}$, em 1984 foram publicados dois expedientes - a Resolução sobre o ensino superior e o desenvolvimento da cooperação universitária na Comunidade Europeia, e a Resolução sobre o reconhecimento acadêmico de diplomas e de períodos de estudo - e, em 1985, o Parlamento foi responsável por convocar a Conferência sobre Cooperação no Ensino Superior na CEE, com o objetivo de promover, junto 
aos Estados-membros, ações mais urgentes e amplas relativas à cooperação universitária e à mobilidade estudantil na Comunidade. (CEE, 1987).

De acordo com Riedo e Pereira (2009), tais resoluções surgiram no intuito de estimular, em última instância, a ideia de um modelo cultural que atendesse aos pressupostos de integração europeia, ainda que dentre a abrangência da respectiva comunidade (CEE). A ascensão a esse modelo implicaria, também, a conseguinte harmonização dos sistemas de ensino, a qual seria viabilizada por meio da promoção da correspondência entre os ciclos de cada sistema nacional, de mecanismos de reconhecimento de títulos, e do incentivo à livre circulação de estudantes, docentes e pesquisadores.

É importante frisar que, nessa primeira fase, as convenções e demais expedientes relativos ao reconhecimento de qualificações e períodos de estudo, por serem emanadas no âmbito das comunidades europeias vigentes, restringiam-se a seus respectivos Estados-membros. Ou seja, a dimensão europeia, tratada nesses expedientes, referia-se a uma área circunscrita aos Estados-membros dessas comunidades, sendo que os demais países europeus estavam, até então, periféricos a essas políticas. Uma maior abertura à participação de demais países aconteceria no final da década de 1980, com a criação do Programa Erasmus, em 1987.

Considerando-se o exposto até então, têm-se, no seguinte quadro, os expedientes sobre educação superior referentes à primeira fase:

Quadro 1 - Referências do Processo de Bolonha - primeira fase (1953-1985)

\begin{tabular}{|cl|l|l|}
$\mathbf{A n o}$ & Instância & \multicolumn{1}{c|}{ Expediente } & \multicolumn{1}{c|}{ Tema } \\
$\mathbf{1 9 5 3}$ & $\begin{array}{l}\text { Conselho } \\
\text { Europeu }\end{array}$ & $\begin{array}{l}\text { Equivalência Europeia sobre } \\
\text { dão acesso a Estabelecimentos } \\
\text { Universitários }\end{array}$ & $\begin{array}{l}\text { Equivalência de diplomas } \\
\text { secundários }\end{array}$ \\
$\mathbf{1 9 5 4}$ & $\begin{array}{l}\text { Conselho } \\
\text { Europeu }\end{array}$ & $\begin{array}{l}\text { Convenção Cultural Europeia } \\
\mathbf{1 9 5 5}\end{array}$ CECA & $\begin{array}{l}\text { Facilitar a participação em } \\
\text { atividades culturais }\end{array}$ \\
\hline Conferência de Messina & $\begin{array}{l}\text { Harmonizar políticas sociais } \\
\text { e instituições comuns; univer- } \\
\text { sidade com 'mentalidade } \\
\text { europeia' }\end{array}$ \\
\hline
\end{tabular}




\begin{tabular}{|c|c|c|c|}
\hline Ano & Instância & Expediente & Tema \\
\hline 1956 & $\begin{array}{l}\text { Conselho } \\
\text { Europeu }\end{array}$ & $\begin{array}{l}\text { Convenção Europeia sobre } \\
\text { Equivalência de Períodos de Es- } \\
\text { tudos Universitários }\end{array}$ & $\begin{array}{l}\text { Reconhecimento de estudos } \\
\text { de línguas em outras IES }\end{array}$ \\
\hline \multirow{2}{*}{1959} & $\begin{array}{l}\text { Conselho } \\
\text { Europeu }\end{array}$ & $\begin{array}{l}\text { Convenção Europeia sobre o } \\
\text { Reconhecimento Acadêmico de } \\
\text { Qualificações Universitárias }\end{array}$ & $\begin{array}{l}\text { Reconhecimento de habilita } \\
\text { ções de nível superior entre } \\
\text { diferentes universidades }\end{array}$ \\
\hline & $\begin{array}{l}\text { Conferência } \\
\text { de Reitores }\end{array}$ & $\begin{array}{l}\text { Primeira reunião da Conferência } \\
\text { de Reitores das Universidades Eu- } \\
\text { ropeias }\end{array}$ & $\begin{array}{l}\text { Propostas de acordos inter- } \\
\text { universitários }\end{array}$ \\
\hline 1961 & CEE & Declaração de Bonn & $\begin{array}{l}\text { Cooperação e integração } \\
\text { europeia na instrução, cul } \\
\text { tura e pesquisa }\end{array}$ \\
\hline 1963 & CEE & $\begin{array}{l}\text { Decisão } 63 / 266 / C E E \text { sobre } \\
\text { graus de formação profissional }\end{array}$ & $\begin{array}{ll}\text { Relacionar } & \text { formação } \\
\text { acadêmica às } & \text { atividades } \\
\text { profissionais } & \end{array}$ \\
\hline 1974 & UNESCO & $\begin{array}{l}\text { Convenção Regional para o Re- } \\
\text { conhecimento de Estudos, Títulos } \\
\text { e Diplomas da Educação Supe- } \\
\text { rior na América Latina e Caribe }\end{array}$ & $\begin{array}{l}\text { Reconhecimento de estudos } \\
\text { e diplomas }\end{array}$ \\
\hline \multirow[b]{2}{*}{1976} & CEE & $\begin{array}{l}\text { Resolução com vistas à Comissão } \\
\text { promover cooperação universi- } \\
\text { tária }\end{array}$ & $\begin{array}{l}\text { Cooperação interuniversi- } \\
\text { tária }\end{array}$ \\
\hline & UNESCO & $\begin{array}{l}\text { Convenção Internacional sobre } \\
\text { Reconhecimento de Estudos, Di- } \\
\text { plomas e Graus de Ensino Su- } \\
\text { perior nos Estados Árabes e nos } \\
\text { Estados Europeus Ribeirinhos do } \\
\text { Mediterrâneo }\end{array}$ & $\begin{array}{l}\text { Reconhecimento de estudos } \\
\text { e diplomas }\end{array}$ \\
\hline 1979 & UNESCO & $\begin{array}{l}\text { Convenção sobre o Reconhe- } \\
\text { cimento de Estudos e Diplomas } \\
\text { Relativos ao Ensino Superior nos } \\
\text { Estados da Região Europa }\end{array}$ & $\begin{array}{l}\text { Reconhecimento de estudos } \\
\text { e diplomas; criação de ter } \\
\text { minologia e de critérios de } \\
\text { avaliação comuns; equipa } \\
\text { rar estudos, diplomas e títu } \\
\text { los; considerar experiências } \\
\text { e competências individuis } \\
\text { prévias, bem como estudos } \\
\text { parciais }\end{array}$ \\
\hline
\end{tabular}




\begin{tabular}{|c|c|c|c|}
\hline Ano & Instância & Expediente & Tema \\
\hline 1983 & CEE & $\begin{array}{l}\text { Medidas para promoção da mo- } \\
\text { bilidade no domínio do ensino } \\
\text { superior }\end{array}$ & $\begin{array}{l}\text { Cooperação interuniversi- } \\
\text { tária para incentivar a mo- } \\
\text { bilidade }\end{array}$ \\
\hline \multirow{3}{*}{1984} & $\begin{array}{l}\text { Parlamento } \\
\text { Europeu }\end{array}$ & $\begin{array}{l}\text { Resoluções sobre ensino superior, } \\
\text { desenvolvimento da cooperação } \\
\text { universitária e reconhecimento } \\
\text { acadêmico de diplomas e de } \\
\text { períodos de estudo na CEE }\end{array}$ & $\begin{array}{l}\text { Cooperação interuniversi- } \\
\text { tária; Reconhecimento de } \\
\text { estudos e diplomas }\end{array}$ \\
\hline & $\begin{array}{l}\text { Comissão } \\
\text { Europeia }\end{array}$ & $\begin{array}{l}\text { Rede de Centros Nacionais de } \\
\text { Informação sobre Reconhecimen- } \\
\text { to Acadêmico - NARIC }\end{array}$ & $\begin{array}{l}\text { Informações e declarações } \\
\text { sobre sistemas de educação } \\
\text { superior e respectivas quali- } \\
\text { ficações }\end{array}$ \\
\hline & $\begin{array}{l}\text { Parlamento } \\
\text { Europeu }\end{array}$ & $\begin{array}{l}\text { Conferência sobre Cooperação } \\
\text { no Ensino Superior na Comu- } \\
\text { nidade Europeia - cooperação } \\
\text { universitária e mobilidade dos } \\
\text { estudantes na CEE }\end{array}$ & $\begin{array}{l}\text { Cooperação interuniversi- } \\
\text { tária para incentivar a mo- } \\
\text { bilidade }\end{array}$ \\
\hline
\end{tabular}

Fonte | Elaborado a partir de Siebiger (2013)

II - Segunda Fase: 1987 a 1998 - Diferentemente da exposição referente à

primeira fase, nesse momento, em vez de entidades, dá-se ênfase nos expedientes publicados, uma vez que as medidas apresentadas não mais se restringem às nações circunscritas às comunidades europeias, mas, expandem-se a outros países, tanto europeus como de outros continentes.

Primeiramente, em 1987, é lançado, sob competência da Comissão Europeia, o Programa de Ação Comunitário em Matéria de Mobilidade dos Estudantes (European Community Action Scheme for the Mobility of University Students), conhecido como Programa Erasmus. (CEE, 1987). Atualmente em pleno funcionamento, o Programa compreende um conjunto de ações com o objetivo de viabilizar a mobilidade estudantil na Europa: a) criação de uma rede universitária, mediante acordos interinstitucionais; b) reconhecimento acadêmico de diplomas e períodos de estudos universitários realizados em outro Estado-membro, por meio do sistema de transferência de créditos acadêmicos em nível de Comunidade (ECTS), então numa base experimental e voluntária; c) oferta de bolsas de estudo a estudantes, custeadas pela CEE. (CEE, 1987). 
Com o Erasmus, previu-se também a adoção de um modelo de mensuração, acumulação e transferência de créditos, ainda em caráter experimental que, posteriormente, em 1989, converteu-se no sistema ECTS (European Credit Transfer System). Esse sistema estabeleceu uma medida-padrão para aferir as atividades acadêmicas em créditos: atualmente, 1 (um) crédito corresponde de 25 a 30 horas de trabalho anuais; por sua vez, o ano letivo compreende cerca de 60 créditos anuais, ou 30 créditos por semestre; assim, a carga de trabalho de um estudante oscila entre 1500 e 1800 horas por ano letivo, ou 750/900 horas por semestre letivo.

Na matriz do ECTS, atribuem-se créditos às diversas naturezas de atividades letivas, sejam programas de estudo plenos e/ou componentes educacionais (tais como módulos, disciplinas, unidades curriculares, etc.), as quais são calculadas em termos de carga horária de trabalho do estudante latividades letivas que incluiriam aulas, seminários, projetos, estudos individuais, avaliações, trabalho de dissertação, estágios laborais, trabalhos de laboratório, etc.) e de acordo com os resultados de aprendizagem estabelecidos, sendo possível sua transferência entre programas, instituições, e países. ICOMISSÃO EUROPEIA, 1989).

Programa Erasmus, atualmente em plena vigência, expandiu seu alcance a países externos à UE por meio do subcomponente denominado de Erasmus Mundus. Esse subprograma constitui-se, desde o início da reforma, num dos principais mecanismos de viabilização da mobilidade estudantil no âmbito do processo de Bolonha, uma vez que, além de possibilitar o trânsito estudantil, agrega também a incumbência de averiguar a equivalência entre os diferentes sistemas e currículos de educação superior europeus.

Ainda na década de 1980, é publicada a Magna Charta Universitatum, um documento elaborado pela Universidade de Bolonha, em 1986, com o objetivo de estabelecer princípios fundamentais a serem respeitados pelas universidades de modo geral. Assim, em 1988, por ocasião da comemoração dos 900 anos daquela universidade, houve a assinatura da Charta por aproximadamente 400 IES europeias, tornando-se uma carta de princípios e medidas em defesa da autonomia dessas instituições. (MAGNA CHARTA, 1988).

Em termos sucintos, os princípios constantes da Charta, e que deveriam sustentar a vocação da Universidade, são: a) a universidade como 
instituição autônoma que, de modo crítico, produz e transmite a cultura através da investigação e do ensino, e como instituição independente de qualquer poder políitico, econômico ou ideológico; b) indissociabilidade entre ensino e pesquisa; c) respeito à liberdade acadêmica de ensinar e pesquisar; e, d) ser compreendida como uma instituição que transcende fronteiras geográficas e políticas em favor do conhecimento recíproco e da interação entre as diferentes culturas. (MAGNA CHARTA, 1988).

A Magna Charta tornou-se, assim, uma declaração universal de princípios fundamentais das Universidades não apenas na Europa, mas também em outras regiões do mundo (atualmente, a Charta conta com a adesão de 752 universidades, em 80 países). Há, inclusive, universidades brasileiras que são signatárias, entre elas, a Universidade de São Paulo (USP), a Universidade Estadual de Campinas (Unicamp), a Universidade Federal do Espírito Santo (UFES) e a Universidade Federal do Rio de Janeiro (UFRJ). E esses princípios seriam, posteriormente, tomados como referência na Declaração de Bolonha.

Na sequência, o início da década de 1990 foi marcado com a publicação, pelo Conselho Europeu, da Convenção Europeia sobre Equivalência Geral de Períodos de Estudos Universitários (CONSELHO EUROPEU, 1990), com o objetivo de ampliar o diálogo e os acordos internacionais em matéria de educação superior, iniciados em 1987 com o programa Erasmus, e que posteriormente, em 1992, se consolidariam nas diretrizes do Tratado de Maastricht sobre educação. (COMISSÃO EUROPEIA, 1997; EUROPA, 1992).

Para tanto, o Tratado que criou a União Europeia estabeleceu, em seu Art. 126, que as ações da UE, em regime de colaboração com os Estadosmembros, teriam a finalidade de promover a dimensão europeia da educação por meio do incentivo ao aprendizado de línguas, mobilidade, cooperação interinstitucional, educação a distância, cooperação com países terceiros e organismos internacionais, além de constar um artigo específico (Art. 127) que se refere às políticas de formação profissional, no sentido de se revisar os perfis de formação com vistas a facilitar a inserção de seus egressos no mercado de trabalho. (EUROPA, 1992).

Dois anos após, é lançado o programa Socrates, que reuniu os demais programas educacionais vigentes (Erasmus, Comenius e Lingua), e adicionou outros dois, referentes à utilização de tecnologias para fins pedagógicos e à educação de adultos (Minerva e Grundtvig). (PARLAMENTO EUROPEU E 
CONSELHO DA UE, 1994). O programa Socrates é a efetivação, ipsis litteris, das diretrizes para a educação previstas no Art. 126 do Tratado de Maastricht referentes à promoção da dimensão europeia em todos os níveis educacionais.

Realizado em duas fases entre 1999 e 2006, o programa compreendeu, especialmente para a educação superior, duas medidas: promoção da dimensão europeia dentre as universidades e o incentivo à mobilidade estudantil, ambas por meio de financiamento de bolsas dentre o Programa Erasmus. Essas medidas tiveram por objetivo promover o Sistema Europeu de Transferência de Créditos (ECTS), estimular o desenvolvimento conjunto de programas de estudos superiores e incentivar as universidades a desenvolver atividades transnacionais destinadas a conferir uma dimensão europeia em todas as áreas de estudo. Tais objetivos seriam alcançados, dentre outras ações, mediante a previsão, nos currículos, de materiais que favorecessem a compreensão das especificidades culturais, artísticas, políticas, econômicas e sociais dos demais Estados-membros (trabalhados dentre módulos pluridisciplinares ou interdisciplinares). (COMISSÃO EUROPEIA, 2009).

Posteriormente, em 2007, o Programa Socrates foi substituído pelo Programa de Aprendizagem ao Longo da Vida (Lifelong Learning Program) 46 - LLP, com vigência prevista para o período de 2007-2013. As ações dos mencionados subprogramas pertencentes ao Socrates, além de outros programas de educação e formação promovidos pela UE, foram incorporadas ao LLP (COMISSÃO EUROPEIA, 2009; PARLAMENTO EUROPEU E CONSELHO DA UE, 1994).

Na segunda metade da década de 1990, a Unesco reaparece como protagonista na discussão sobre os rumos da educação superior mundial, manifestando-se por meio da publicação de dois relatórios, frutos de estudos encomendados - os informes Delors (1996) - Educação: um tesouro a descobrir - relatório elaborado para a UNESCO da Comissão Internacional sobre Educação para o Século XXI, sob coordenação de Jacques Delors, então presidente da Comissão Europeia (UNESCO, 2010), e Attali (1998) - elaborado por um grupo de consultores franceses, sob a coordenação do Professor Jacques Attali, o qual consiste num estudo encomendado pelo governo francês que, a partir de uma avaliação do sistema de ensino desse país, propôs uma visão a longo prazo para o ensino superior europeu como um todo. 
No primeiro, além do estabelecimento de quatro pilares para a educação - aprender a conhecer, aprender a fazer, aprender a conviver e aprender a ser ${ }^{7}$, a educação superior, em específico, é pensada em termos fundamentais, no sentido de que a formação, nesse nível de ensino, devesse conciliar o 'saber ser' com o 'saber fazer', muito embora num horizonte de maior diversificação da oferta de cursos e conteúdos para atender demandas dos setores econômicos dentre a perspectiva de aprendizagem ao longo da vida. Nesse relatório, põem-se em evidência as disparidades dos sistemas educacionais para se justificar a adoção de medidas de comparabilidade, de equivalência, bem como de harmonização dos textos legislativos nacionais com os acordos internacionais, ou seja, prever-se, juridicamente, a adoção dos termos das convenções supranacionais na área de educação superior dentre a legislação dos Estados nacionais. Esse relatório também sugeriu a realização de um debate compreendendo comunidade acadêmica, ministérios e organismos internacionais sobre perspectivas de reformas urgentes na educação superior.

No segundo, a educação superior é pensada em termos estruturais, propondo-se uma organização em ciclos, na qual a formação em nível superior seria encurtada lo chamado "esquema 3-5-8", sendo três anos para a licenciatura, dois anos para o mestrado e três anos para o doutoradol e caracterizada por um perfil mais profissionalizante. Além disso, recomendou-seno relatório que as IES, em vez de instituições estatais, devessem converter-se em uma espécie de entidades paraestatais, sem garantia de financiamento direto do Estado. Para receber financiamento, as universidades teriam de firmar contratos quadrienais com o Estado, nos quais seriam estabelecidas metas a serem alcançadas. $O$ recebimento de recursos ficaria, portanto, condicionado ao seu desempenho/mérito tanto no cumprimento dos contratos como em avaliações sistemáticas externas conduzidas por agências independentes, prevendo-se, inclusive, como um dos quesitos de avaliação, a devida revisão, em conjunto com empresas, da oferta de formação em nível superior. Em última instância, tais aspectos teriam por finalidade redefinir as IES como "centros de aprendizagem ao longo da vida".

Em suma, ambos os relatórios compreendem a educação superior como serviço basicamente de formação profissional para o mercado de trabatho - seja em nível de graduação ou pós-graduação - numa arena em que a competitividade é requisito para a sobrevivência das IES perante os "desafios 
da globalização" na aclamada "Sociedade do Conhecimento", de acordo com a retórica neoliberal.

Entre ambos os relatórios, em 1997, foi publicada a Convenção sobre Reconhecimento das Qualificações Relativas ao Ensino Superior na Região Europa - Convenção de Lisboa, que, por meio do estabelecimento de um acordo sobre reconhecimento de estudos e diplomas nos países pertencentes à região europeia atendida pela Unesco, tem por objetivo estimular a mobilidade acadêmica. (KOPPE, 2008; PORTUGAL, 1997).

Nessa convenção, criou-se o Suplemento ao Diploma, que se trata de um documento de formato padrão para todos os países signatários da respectiva convenção, redigido na língua oficial do país de origem e em inglês, e expedido, obrigatoriamente, junto ao Diploma, no qual devem constar as características do curso e da universidade onde o estudante concluiu sua qualificação, a estrutura do curso (conteúdo, módulos, unidades curriculares, estágios, etc.), os créditos ECTS integralizados, as competências adquiridas (grau acadêmico e/ou profissional), as atividades extracurriculares desenvolvidas, bem como os conceitos e notas recebidos pelo estudante. Esse documento tem a finalidade de traduzir, aos empregadores, os estudos acadêmicos reali-

48 zados em termos de competências adquiridas e resultados de aprendizagem aferidos dentre a formação universitária. (PORTUGAL, 1997).

Além da adoção do Suplemento ao Diploma, essa convenção estabeleceu como exigência aos Estados signatários a criação de seus respectivos centros NARIC, devidamente integrados em rede (ENIC). (PORTUGAL, 1997).

Vale ressaltar que as convenções expedidas no âmbito do Conselho e do Parlamento europeus, bem como os programas sob competência da Comissão Europeia, concebem a educação superior como estratégia para promover, além da própria qualificação, a mobilidade e empregabilidade de pessoas entre os países europeus, evitando-se assim a evasão de estudantes, professores e pesquisadores a outros continentes la denominada "fuga de cérebros"), nomeadamente a outros polos educacionais concorrentes tais como Estados Unidos da América, Austrália, Nova Zelândia, Japão e, atualmente, China.

Por fim, tem-se, em 1998, a realização da Conferência Mundial de Educação Superior. Sob coordenação da Unesco, e realizada poucos meses antes da assinatura da Declaração de Sorbonne, essa conferência representou 
um evento com vistas a subsidiar um movimento de reforma na educação superior em nível mundial, a qual deveria ser repensada em função do atendimento às "novas exigências da sociedade do conhecimento". Na declaração da conferência, defendeu-se o fortalecimento dos vínculos da academia com o mundo do trabalho, de modo a inspirar revisões estruturais e curriculares, tais como o desenvolvimento de habilidades empresariais nos estudantes, a diversificação institucional e a criação de agências independentes responsáveis pela avaliação de qualidade. Também foi reforçada a necessidade de ratificação, por parte dos Estados-nação, das convenções vigentes relativas ao reconhecimento de estudos e de diplomas, com o objetivo de promover a dimensão europeia da educação, a ser materializada notadamente por meio da mobilidade estudantil. (UNESCO, 1998).

Em suma, a partir das referências apresentadas, tem-se, no seguinte quadro, os expedientes sobre educação superior dessa segunda fase de maior expansão das políticas para a área:

Quadro 2 - Referências do Processo de Bolonha - segunda fase (1987-1998)

\begin{tabular}{|c|c|c|c|}
\hline Ano & Instância & Expediente & Tema \\
\hline 1987 & Comissão Europeia & Programa Erasmus & $\begin{array}{l}\text { Equivalência de diplomas } \\
\text { secundários }\end{array}$ \\
\hline 1988 & Universidades & $\begin{array}{l}\text { Magna Charta Universi- } \\
\text { tatum }\end{array}$ & $\begin{array}{l}\text { Facilitar a participação em ativi- } \\
\text { dades culturais }\end{array}$ \\
\hline 1989 & Coselho Europeu & $\begin{array}{l}\text { European Credit Transfer } \\
\text { System - ECTS }\end{array}$ & $\begin{array}{l}\text { Harmonizar políticas sociais e } \\
\text { instituições comuns; universidade } \\
\text { com 'mentalidade europeia' }\end{array}$ \\
\hline 1990 & União Europeia & $\begin{array}{l}\text { Convenção Europeia so- } \\
\text { bre Equivalência Geral } \\
\text { de Períodos de Estudos } \\
\text { Universitários }\end{array}$ & $\begin{array}{l}\text { Reconhecimento de estudos de } \\
\text { línguas em outras IES }\end{array}$ \\
\hline 1992 & Conselho Europeu & Tratado de Maastricht & $\begin{array}{l}\text { Dimensão europeia da educa- } \\
\text { ção; aprendizado de línguas; mo- } \\
\text { bilidade; educação à distância; } \\
\text { cooperação com países terceiros } \\
\text { e organismos internacionais; } \\
\text { política de formação profissional }\end{array}$ \\
\hline
\end{tabular}




\begin{tabular}{|c|c|c|c|}
\hline Ano & Instância & Expediente & Tema \\
\hline 1994 & União Europeia & Programa Socrates & $\begin{array}{l}\text { Dimensão europeia em todos os } \\
\text { níveis educacionais; mobilidade; } \\
\text { aprendizado de línguas; reconhe- } \\
\text { cimento de estudos e diplomas; } \\
\text { cooperação interuniversitária }\end{array}$ \\
\hline 1996 & UNESCO & $\begin{array}{l}\text { Educação: um tesouro } \\
\text { a descobrir - Relatório } \\
\text { Delors }\end{array}$ & $\begin{array}{l}\text { Qualificação para atender neces- } \\
\text { sidades da economia; educação } \\
\text { ao longo da vida }\end{array}$ \\
\hline 1997 & $\begin{array}{c}\text { Conselho Europeu/ } \\
\text { UNESCO }\end{array}$ & Convenção de Lisboa & $\begin{array}{l}\text { Mobilidade; reconhecimento de } \\
\text { estudos e diplomas; Suplemento } \\
\text { ao Diploma; Rede de Centros } \\
\text { NARIC }\end{array}$ \\
\hline 1998 & UNESCO & $\begin{array}{l}\text { Pour um modele européen } \\
\text { d'enseignementsupérieur }\end{array}$ & $\begin{array}{l}\text { Propostas de: sistema de ciclos } \\
3 / 5 / 8 \text {; contratos quadrienais } \\
\text { entre IES e Estados; IES como } \\
\text { centros de formação ao longo } \\
\text { da vida; validação da experiên- } \\
\text { cia profissional pela academia; } \\
\text { avaliação externa por agências } \\
\text { heterogêneas; financiamento de } \\
\text { acordo com o desempenho/méri- } \\
\text { to institucional }\end{array}$ \\
\hline 1998 & $\begin{array}{l}\text { Ministros da } \\
\text { Educação }\end{array}$ & $\begin{array}{l}\text { Declaração de Sor- } \\
\text { bonne }\end{array}$ & $\begin{array}{l}\text { Mobilidade estudantil; remoção } \\
\text { de barreiras à livre circulação; re- } \\
\text { conhecimento mútuo de sistemas } \\
\text { de educação superior; sistema de } \\
2 \text { ciclos; sistema de créditos; re- } \\
\text { conhecimento de estudos e títulos } \\
\text { entre IES, lo ciclo profissionali- } \\
\text { zante; encurtar a formação stricto } \\
\text { sensu; quadro de referência para } \\
\text { qualificações universitárias, cria- } \\
\text { ção do EEES; competitividade da } \\
\text { educação superior europeia no } \\
\text { mundo }\end{array}$ \\
\hline
\end{tabular}




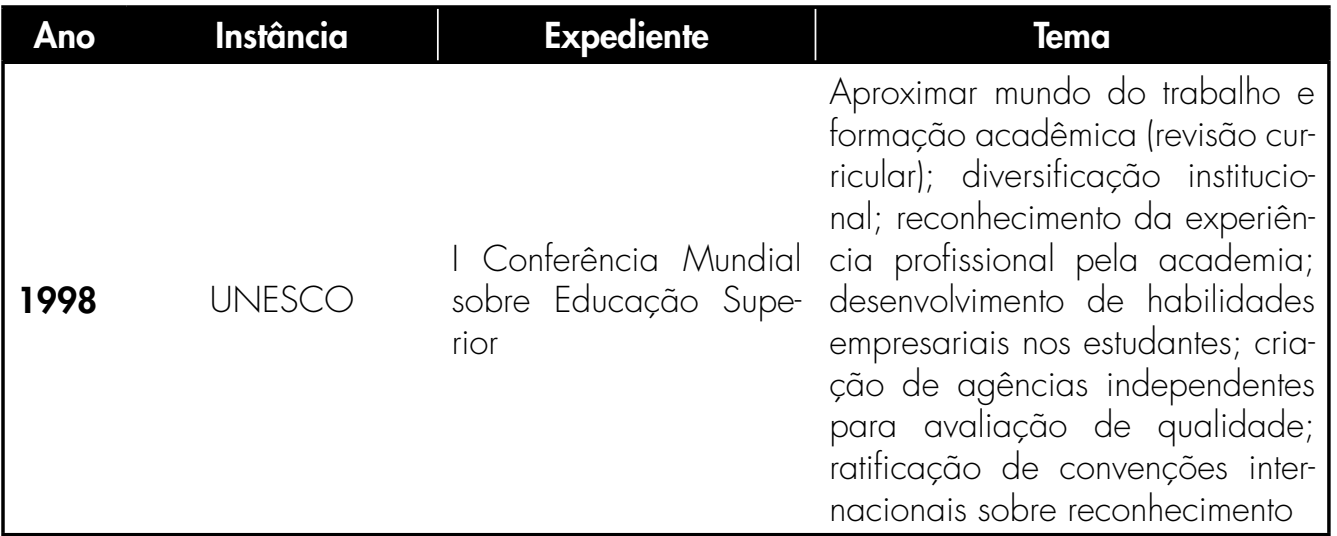

Fonte | Elaborado a partir de Siebiger (2013)

\section{E, então, tem-se a reforma (ou reestruturação)}

Conforme o exposto até aqui, pôde-se observar que o processo de Bolonha se sustenta no próprio movimento histórico de constituição das comunidades europeias e, mais recentemente, de sua unificação. Ou seja, embora não seja uma iniciativa da UE, a reforma consiste, também, em uma iniciativa de unificação, sobretudo do ponto de vista econômico-educacional, considerando-se que as iniciativas de integração europeia desencadeadas pelo Tratado de Maastricht - que, ao criar a União Europeia, constituiu um grupo de maior abrangência se comparado às comunidades europeias antecedentes (atualmente, 27 países fazem parte da UE) - compreendem o estabelecimento de uma moeda comum (Euro), a realização de um pleno mercado interno, e a remoção de entraves em questões aduaneiras e de circulação de produtos, serviços e pessoas (leia-se, aqui, de profissionais). E, no que diz respeito à educação, seus dispositivos advogam a promoção de uma dimensão europeia em todos os níveis e modalidades educacionais, considerando os termos dos artigos 126 e 127 mencionados anteriormente.

Vale ressaltar que os quatro países que assinaram a Declaração de Sorbonne (Alemanha, França, Inglaterra e Itália) são Estados-nação integrantes da UE e, portanto, a orientação geral em torno das políticas econômico-sociais seguem os pressupostos definidos por seu tratado de unificação. Dessa forma, as políticas no campo da educação têm por finalidade última atender à própria 
razão de ser desse tratado: a consolidação do mercado único europeu em todos os seus aspectos, o que inclui a formação de profissionais para atender a essa perspectiva.

Nesse sentido, nota-se que, anteriormente ao processo de Bolonha, as próprias convenções e demais acordos supranacionais sobre educação superior já vinham se ampliando em termos de abrangência, tanto nos assuntos que buscam conciliar, como na quantidade de países signatários. $\bigcirc$ próprio movimento de reforma é um acordo que, desde a Declaração de Bolonha, transcende os limites da UE: atualmente, são 48 (quarenta e oito) países signatários da Declaração de Bolonha, sendo todos os 27 (vinte e sete) países integrantes da UE, e 21 (vinte e um) países europeus e asiáticos não integrantes da UE. Inclusive, para ser signatário do processo de Bolonha, não é necessário ser Estado-membro da União Europeia; basta que, por meio de assinatura, concorde com os objetivos expressos na Declaração de Bolonha e nos comunicados posteriores e busque alcançá-los em seu território. (FRONZAGLIA, 20111 .

Assim, praticamente são três os documentos que definem os objetivos da reforma: as declarações de Sorbonne (1998), de Bolonha (1999), e o

52 Comunicado da primeira conferência de ministros dos países signatários da reforma, realizada em Praga (2001).

Na Declaração de Sorbonne, a ênfase recaiu sobre a necessidade de se ampliar as estratégias para o reconhecimento de estudos universitários, diplomas e títulos entre IES e países, a defesa de um o primeiro ciclo (licenciatura) voltado à formação profissional, o 'enxugamento' da formação stricto sensu e a adoção de um quadro de referência para qualificações universitárias, dentre outros aspectos que, posteriormente, se converteram em objetivos expressos na Declaração de Bolonha.

E, dos seis objetivos estabelecidos na Declaração de Bolonha (1999) - estabelecimento de regimes de créditos, ciclos e graus, estímulo à mobilidade estudantil, adoção do suplemento ao diploma, e promoção de uma perspectiva europeia de educação superior - foram acrescidos outros três, por ocasião da conferência realizada em Praga (2001): refletir sobre a educação superior numa perspectiva de aprendizagem ao longo da vida, aumentar a participação de estudantes e universidades na discussão e implementação da reforma, e prever estratégias para seu alcance e visibilidade mundial. 
Para tanto, realizando-se correlações entre os objetivos do processo de Bolonha e os expedientes citados tem-se, dentre os limites das referências apresentadas, o seguinte quadro:

Quadro 3 - Objetivos da reforma e principais referências

\begin{tabular}{|c|c|c|}
\hline Documento & Objetivo & Principal(is) Referência(s) \\
\hline \multirow{4}{*}{$\begin{array}{l}\text { Declaração de } \\
\text { Sorbonne }\end{array}$} & $\begin{array}{l}\text { Reconhecimento de } \\
\text { estudos, diplomas e } \\
\text { títulos entre diferen- } \\
\text { tes IES e países }\end{array}$ & $\begin{array}{l}\text { Convenções do Conselho Europeu - 1953, } \\
1956 \text { e 1959; Resolução do Parlamento Euro- } \\
\text { peu (1984); Convenções da UNESCO - 1974, } \\
1976 \text { e 1979; Programa Erasmus (1987); ECTS } \\
\text { (1989); Convenção de 1990; Tratado de Maas- } \\
\text { tricht (1992); Programa Socrates (1994); Con- } \\
\text { venção de Lisboa (1997) }\end{array}$ \\
\hline & $\begin{array}{l}1^{\circ} \text { ciclo profissionali- } \\
\text { zante }\end{array}$ & $\begin{array}{l}\text { Relatório Attali (1998) } \\
\text { CMES (1998) }\end{array}$ \\
\hline & $\begin{array}{l}\text { Encurtar a formação } \\
\text { stricto sensu }\end{array}$ & Relatório Attali (1998) \\
\hline & $\begin{array}{l}\text { Quadro de referên- } \\
\text { cia para qualifica- } \\
\text { ções universitárias }\end{array}$ & Convenção do Conselho Europeu (1959) \\
\hline \multirow{5}{*}{$\begin{array}{l}\text { Declaração de } \\
\text { Sorbonne e de } \\
\text { Bolonha }\end{array}$} & Sistema de créditos & ECTS (1989) \\
\hline & Sistema de ciclos & Relatório Attali (1998) \\
\hline & $\begin{array}{l}\text { Sistema de graus / } \\
\text { quadro de referên- } \\
\text { cia para qualifica- } \\
\text { ções acadêmicas }\end{array}$ & $\begin{array}{l}\text { Convenções da UNESCO - 1974, } 1976 \text { e } \\
1979\end{array}$ \\
\hline & $\begin{array}{l}\text { Estimular a mobi- } \\
\text { lidade estudantil / } \\
\text { remover barreiras à } \\
\text { livre circulação de } \\
\text { pessoas }\end{array}$ & $\begin{array}{l}\text { Convenção Cultural Europeia (1954); Conferên- } \\
\text { cia de Cooperação para Educação Superior na } \\
\text { CEE (1985); Programa Erasmus (1987); ECTS } \\
\text { (1989); Tratado de Maastricht (1992); Programa } \\
\text { Socrates (1994); Relatório Attali (1998) }\end{array}$ \\
\hline & $\begin{array}{l}\text { Promoção da di- } \\
\text { mensão europeia na } \\
\text { educação superior } \\
\text { Espaço europeu de } \\
\text { educação superior } \\
\text { (EEES) }\end{array}$ & $\begin{array}{l}\text { Programa Erasmus (1 987); Tratado de Maastricht } \\
\text { (1992); Programa Socrates (1994); Convenção } \\
\text { de Lisboa (1997); CMES (1998) }\end{array}$ \\
\hline
\end{tabular}




\begin{tabular}{|c|c|c|}
\hline Documento & Objetivo & Principal(is) Referência(s) \\
\hline $\begin{array}{l}\text { Declaração de } \\
\text { Bolonha }\end{array}$ & $\begin{array}{l}\text { Adoção do Suple- } \\
\text { mento ao Diploma }\end{array}$ & Convenção de Lisboa (1997) \\
\hline \multirow{3}{*}{$\begin{array}{l}\text { Comunicado de } \\
\text { Praga }\end{array}$} & $\begin{array}{ll}\text { Educação superior } \\
\text { na perspectiva de } \\
\text { aprendizagem ao } \\
\text { longo da vida }\end{array}$ & Relatório Delors (1996); Relatório Attali (1998) \\
\hline & $\begin{array}{l}\text { Maior participação } \\
\text { da comunidade } \\
\text { acadêmica na im- } \\
\text { plementação da re- } \\
\text { forma }\end{array}$ & Relatório Delors (1996) \\
\hline & $\begin{array}{l}\text { Alcance e visibi- } \\
\text { lidade internacional } \\
\text { da reforma }\end{array}$ & Naric/Enic (1984) \\
\hline
\end{tabular}

Fonte | Elaborado a partir de Siebiger (2013)

Ao longo desses expedientes, observa-se, histórica e efetivamente, 54 a construção de referências que, posteriormente, tornar-se-iam as principais bases da reforma do processo de Bolonha.

Por um lado, é importante frisar que as influências, ou os antecedentes que contribuíram para sustentar as reformas do processo de Bolonha, de modo algum se esgotam nos expedientes apresentados. Há um expressivo contingente de referências, sobretudo expedidas por organismos de caráter predominantemente econômico - Organização para a Cooperação e Desenvolvimento Econômico (OCDE), Banco Mundial (BIRD), Fundo Monetário Internacional (FMI), Organização Mundial do Comércio (OMC), Acordo Geral de Comércio de Serviços (AGCS) - que, historicamente, emitem recomendações e estabelecem evidentes influências no que se refere aos rumos das políticas sociais, tornando-se efetivas balizas para as políticas de educação.

Nesse ínterim, é relevante destacar dois episódios que ilustram a predominância de interesses econômicos sobre a educação. Primeiro, a tentativa, em 1999 (mesmo ano da assinatura da Declaração de Bolonha), de incluir a educação superior como um dos setores de comércio e serviços do AcordoGeral de Comércio de Serviços (AGCS), buscando-se desregulamentar definitivamente o setor ou deixá-lo por conta da "autorregulação" do mercado, de acordo com a 
compreensão neoliberal que fundamenta a proposta. Segundo, a declaração da "Estratégia de Lisboa", emitida no ano 2000 pela UE, quando a Europa deveria se tornar a "economia baseada no conhecimento mais competitiva e dinâmica do mundo, capaz de crescimento econômico sustentável com mais e melhores empregos e uma maior coesão social", exigindo-se, para tanto, uma revisão completa do sistema educativo europeu (não apenas em nível superior) e a adoção de políticas de formação ao longo da vida.

Contudo, dentre os limites dessa discussão, os expedientes ora mencionados tratam-se de medidas notadamente pertinentes à educação superior.

Por outro lado, o processo de Bolonha é uma reforma que se caracteriza por abrigar e mesmo associar vários elementos em um único processo, apesar das evidentes disparidades ontológicas entre alguns: mantém práticas já em uso (convenções, programas, etc.), fundamenta-se em relatórios e outros expedientes que se referem a avaliações, cenários e propostas para a educação superior e, ao passo que se vincula às políticas de integração da União Europeia e aos interesses de organismos multilaterais de ordem econômica, busca também respeitar os princípios da Magna Charta Universitatum.

Essas referências se estabelecem como resultado das diferentes concepções e finalidades impressas à educação superior, de acordo com o perfil de cada instância e/ou entidade que se manifesta sobre a área. Nesse sentido, tais expedientes ora pendem para concepções de educação superior enquanto direito social e de instituição universitária inspirada em princípios relacionados ao respeito à liberdade acadêmica, ora pendem para uma orientação pragmática, imediatista, entendendo a educação superior como um bem e/ou serviço com vistas a atender demandas pontuais de empresas e do mercado, e as universidades como instituições paraestatais prestadoras de serviço ondemand. Ou seja, as discrepâncias ideológicas entre a natureza tanto dos expedientes como das instâncias que os emanam expressam o perfil notadamente ambíguo da educação superior europeia, fenômeno que pode ser observado não apenas nos domínios do velho continente, mas também como sintoma generalizado em movimentos de reforma congêneres em outras regiões do mundo.

$\bigcirc$ que se pode e se deve questionar, como objeto permanente de discussão e crítica, são as finalidades da reforma, evidenciando-se quai interesses buscar entender, que concepções de sociedade e de educação se propõe a detender, principalmente, seus antagonismos e contradições. Para tanto, em 
medida equivalente ao ritmo de expansão da reforma, crescem também as leituras do processo, que buscam desvelar suas mais variadas nuances.

Contudo, dentre os limites dessa discussão, não se propôs analisar as questões ideológicas do processo de reforma, muito embora o perfil das referências apresentadas indique, grosso modo, suas respectivas concepções de sociedade e de educação superior. A intenção se traduziu em contribuir para a discussão ao esclarecer que as finalidades, objetivos e medidas em curso no processo de Bolonha representam ações que não se iniciaram a partir da "abertura oficial" do processo de reforma, ao final da década de 1990, mas sim, sustentam-se no próprio movimento de reestruturação e integração do continente europeu, iniciado após o término da segunda-guerra mundial, bem como nas respectivas políticas e expedientes para a educação superior que se estabeleceram consentaneamente. Compreender tal movimento histórico, bem como suas referências, torna-se fundamental para a compreensão das políticas de reforma da educação superior do continente europeu ora em curso.

\section{Notas}

1 Indicado nas referências bibliográficas: Siebiger (2013)

2 A apresentação em duas fases se deu para fins de organização da exposição nesse trabalho, considerando a abrangência das medidas tomadas.

3 Criado em 1949 com o objetivo de promover a unidade e a cooperação na Europa, principalmente em questões relacionadas com os direitos humanos, os assuntos sociais, o ensino e a cultura.

4 Com sede em Paris, França, a Organização das Nações Unidas para a Educação, a Ciência e a Cultura - UNESCO foi criada logo após o término da segunda guerra mundial, em 16 de novembro de 1945, com o objetivo de contribuir para a consolidação da paz, a erradicação da pobreza, o desenvolvimento sustentável e o diálogo intercultural mediante a educação, as ciências, a cultura, a comunicação e a informação.

5 Criada 1967, suas principais atribuições compreendem propor legislação ao Parlamento e ao Conselho, bem como fazer cumprir a legislação europeia, supervisionando a aplicação dos Tratados nos Estados-membros.

6 Iniciou suas atividades ainda no âmbito da Comunidade Econômica Europeia, em 1958, sob a denominação de Assembleia Parlamentar Europeia, transformando-se em Parlamento Europeu em 1962. Órgão parlamentar e legislativo, seu trabalho é realizado por comissões, e, dentre suas atribuições com relação à educação, destaca-se a competência quanto à política de educação da União Europeia, incluindo a área do ensino superior europeu, a promoção do sistema das escolas europeias e a aprendizagem ao longo da vida. 
7 IDe acordo com Mello e Dias (201 1), os princípios 'aprender a conhecer', 'aprender a ser' e 'aprender a fazer' foram mencionados já na década de 1970, por meio do Informe Edgar Faure (1972). Por sua vez, o Informe Delors (1996) acrescentou o princípio 'aprender a viver juntos'.

\section{Referências}

ATTALI, Jaques. Pour un modèle européen d'enseignement supérieur. Paris: Ministère de l'éducationnationale, de larecherche et de latechnologie, 1998. Disponível em: <http:// www.education.gouv.fr/cid 1911 / pour-un-modele-europeen-d-enseignement-superieur.html>. Acesso em: 6 jun. 2013.

COMISSÃO EUROPEIA. COM/2009/0159 final: relatório final sobre a execução e - impacto da segunda fase (2000-2006) dos programas de acção comunitários [...]. Bruxelas: Comissão Europeia, 2009. Disponível em: <http:/ / eur-lex.europa.eu/LexUriServ/ LexUriServ.do?uri=CELEX:52009DC0 159:PT:HTML>. Acesso em: 12 jun. 2013.

European Credit Transferand Accumulation System - ECTS (1989). Disponível em: http://ec.europa.eu/education/lifelong-learning-policy/doc48_en.htm>. Acesso em: 6 jun. 2013.

Sete dias que fizeram a Europa. Bruxelas: Direção-Geral Informação, Comunicação, Cultura e Audiovisual. 1997. (Série A Europa em Movimento).

COMUNIDADE ECONÔMICA EUROPEIA (CEE). 87/327/CEE: Decisão do Conselho de 15 de Junho de 1987 [...] (Erasmus). Luxemburgo: CEE, 1987. Disponível em: <http://eur-lex.europa.eu/LexUriServ/LexUriServ.do?uri=CELEX:3 1987D0327:PT:HTML>. Acesso em: 17 jun. 2013.

CONSELHO EUROPEU. European Convention on the General Equivalence of Periods of University Study (1990). Disponível em: http://conventions.coe.int/Treaty/EN/Treaties/ $\mathrm{Html} / 138 . \mathrm{htm}$. Acesso em: 8 jun. 2013.

Joint ENIC/NARIC charter of activities and services. Estrasburgo: Conselho Europeu, 2004. Disponível em: <https://wcd.coe.int/com.instranet.InstraServlet? command=com. instranet. CmdBlobGet\&Instranetlmage=32022 1 \&SecMode= $1 \&$ Docld=8220 $14 \&$ Usage=2> . Acesso em: 29 ago. 2013.

DIAS SOBRINHO, José. O Processo de Bolonha. In: PEREIRA, Elizabete Monteiro de Aguiar; ALMEIDA, Maria de Lourdes Pinto de. Universidade Contemporânea: políticas do processo de Bolonha. Campinas: Mercado de Letras, 2009. 
EUROPA. Conselho Europeu extraordinário de Lisboa (março de 2000): para uma Europa da inovação e do conhecimento. Disponível em: <http://europa.eu/legislation_summaries/ education_training_youth/general_framework/c10241_pt.htm>. Acesso em: 14 jun. 2013.

Comunicado de Praga, de 19 de maio de 2001. Disponível em: <http://www. ond.vlaanderen.be/hogeronderwijs/bologna/documents/declarations_communiques. htm>. Acesso em: 5 jun. 2013.

Declaração de Bolonha, de 19 de junho de 1999. Disponível em: <http://www. ond.vlaanderen.be/hogeronderwijs/bologna/documents/declarations_communiques. htm>. Acesso em: 5 jun. 2013.

Declaração de Sorbonne, de 25 de maio de 1998. Disponível em: <http://www. ond.vlaanderen.be/hogeronderwijs/bologna/documents/declarations_communiques. htm>. Acesso em: 6 jun. 2013.

Tratado de Maastricht (1992). Disponível em: <http://eur-lex.europa.eu/pt/treaties/dat/1 1992M/htm/1 1992M.htm|\#000100000 1 >. Acesso em: 14 jun. 2013.

FRONZAGLIA, Maurício Loboda. Políticas públicas internacionais: o caso do processo de Bolonha. 310 p. Tese (Doutorado em Ciência Política) - Programa de Pós-Graduação em Ciência Política. Universidade Estadual de Campinas, Campinas, 2011.

KOPPE, Leonardo Renner. Transformações da educação superior na Europa: a reforma da educação superior na Alemanha pós-processo de Bolonha. 156 p. Dissertação (Mestrado em Sociologia) - Programa de Pós-Graduação em Sociologia, Universidade Federal do Rio Grande do Sul, Porto Alegre, 2008.

MAGNA CHARTA. Magna Charta Universitatum - 1988. Disponível em: <http://www. magna-charta.org>. Acesso em: 9 jun. 2013.

MELLO, Alex Fiúza de; DIAS, Marco Antônio Rodrigues. Os reflexos de Bolonha e a América Latina: problemas e desafios. Educação \& Sociedade, Campinas, v. 32, n. 115, p. 413435, abr./jun. 2011.

PARLAMENTO Europeu e Conselho da União Europeia. Posição comum (CE) $\mathbf{n}^{\circ}$ 33/94: adoptada pelo Conselho em 18 de Julho de 1994 que cria o programa de acção comunitária Socrates. S/I. 1994. Disponível em: <http://eurlex.europa.eu/LexUriServ/LexUriServ. do? uri=CELEX:5 1994AG0831\%2805\%29:PT:NOT>. Acesso em: 12 jun. 2013. 
PORTUGAL. Gabinete de Documentação e Direito Comparado. Convenção Cultural Europeia (1954). Disponível em: http://www.gddc.pt/siii/im.asp?id=1577. Acesso em: 14 jun. 2013.

Convenção Europeia sobre Equivalência de Diplomas que dão acesso a Estabelecimentos Universitários - 1953, e seu Protocolo Adicional - 1964 (1981). Disponível em:http://www.gddc.pt/siii/docs/dec98-1981.pdf. Acesso em: 28 ago. 2013.

Convenção Europeia sobre o Reconhecimento Académico de Qualificações Universitárias (1959). Disponível em: http://www.gddc.pt/siii/im.asp?id=1577. Acesso em: 14 jun. 2013.

Convenção sobre o Reconhecimento dos Estudos e Diplomas Relativos ao Ensino Superior nos Estados da Região Europa (1979). Disponível em: <http://www.gddc.pt/ siii/im.asp?id=1316>. Acesso em: 14 jun. 2013.

Resolução da Assembleia da República n. 25/2000, de 30 mar. 2000 - Convenção de Lisboa (1997).Disponível em: <http://www.gddc.pt/siii/docs/rar25-2000.pdf>. Acesso em: 14 jun. 2013.

RIEDO, Cássio Ricardo Fares; PEREIRA, Elizabete Monteiro de Aguiar. O processo de Bolonha e suas consequências na Itália. In:PEREIRA, Elizabete Monteiro de Aguiar; ALMEIDA, Maria de Lourdes Pinto de. Universidade contemporânea: políticas do processo de Bolonha. Campinas: Mercado de Letras, 2009.

SIEBIGER, Ralf Hermes. O processo de Bolonha e a universidade brasileira: aproximações a partir da análise de documentos referenciais. 252 p. Dissertação (Mestrado em Educação) - Programa de Pós-Graduação em Educação, Universidade Federal da Grande Dourados, Dourados, 2013.

UNESCO. Educação: um tesouro a descobrir - relatório para a UNESCO da Comissão Internacional sobre Educação para o Século XXI (1996). Brasília: UNESCO - Representação no Brasil 2010. Disponível em: <http://unesdoc.UNESCO.org/ images/0010/001095/109590por.pdf>. Acesso em: 14 jun. 2013.

Conferência Mundial sobre Educação Superior (1998).Disponível em: <http:// www.direitoshumanos.usp.br/index.php/Direito-a-Educa\%C3\%A7\%C3\%A3o/declaracao-mundial-sobre-educacao-superior-no-seculo-xxi-visao-e-acao.html>. Acesso em: 3 jun. 2013. 
WEIDENFELD, Werner; WESSELS, Wolfgang (Org.). A Europa de A a Z: guia da integração europeia. Comissão Europeia: [s/l]. 1997. Disponível em: <http://www.ucc.ie/ social_policy/Ato\%20Z/pdf/Az_pt.pdf>. Acesso em: 7 jun. 2013.

Me. Ralf Hermes Siebiger

Técnico da Universidade do Estado de Mato Grosso

Campus Universitário do Vale do Teles Píres | Colíder| Mato Grosso Pesquisador do Grupo de Estudos sobre Universidade |GEU/Unemat comparceria com a Universidade Federal do Rio Grande do Sul Integrante do Grupo de Estudos e Pesquisas sobre Políticas e Gestão da Educação da Universidade Federal da Grande Dourados (GEPGE/UFGD)

E-mail | ralfsiebiger@gmail.com

Recebido 12 jul. 2013

Aceito 14 ago. 2013 